Fakultät III

Wirtschaftswissenschaften, Wirtschaftsinformatik und Wirtschaftsrecht

Volkswirtschaftliche Diskussionsbeiträge

Discussion Papers in Economics

No. $179-16$

January 2016

Sebastian G. Kessing · Chiara Strozzi

The Regional Distribution of Public Employment: Theory and Evidence 
Universität Siegen

Fakultät III

Wirtschaftswissenschaften, Wirtschaftsinformatik und Wirtschaftsrecht

Fachgebiet Volkswirtschaftslehre

Hölderlinstraße 3

D-57068 Siegen

Germany

http://www.uni-siegen.de/fb5/vwl/

ISSN 1869-0211

Available for free from the University of Siegen website at http://www.uni-siegen.de/fb5/vwl/research/diskussionsbeitraege/

Discussion Papers in Economics of the University of Siegen are indexed in RePEc and can be downloaded free of charge from the following website:

http://ideas.repec.org/s/sie/siegen.html 


\title{
The Regional Distribution of Public Employment: Theory and Evidence*
}

\author{
Sebastian G. Kessing ${ }^{\dagger} \quad$ Chiara Strozzi ${ }^{\ddagger}$
}

January 25, 2016

\begin{abstract}
We analyze the optimal regional pattern of public employment in an informationconstrained second-best redistribution policy showing that regionally differentiated public employment can serve as an expenditure side tagging device, bypassing or relaxing the equity-efficiency trade-off. The optimal pattern exhibits higher levels of public employment in low productivity regions and is more pronounced the higher is the degree of regional inequality within the country. Empirically, using a panel of European regions from 1995-2007, we find evidence that public employment is systematically higher in low productivity regions. The latter effect is stronger in countries with higher levels of regional inequality.
\end{abstract}

JEL classification: H11, J45, R12

Keywords: Public employment, redistribution, regional inequality, European regions

${ }^{*}$ We would like to thank discussants and participants at the 2011 IIPF conference in Ann Arbor, the BOMOPA Meeting 2011, and seminar participants in Dresden, Magdeburg, Mainz, and Munich for their helpful comments and suggestions. We also thank Malte Zoubek for excellent research assistance. The usual caveat applies. Financial support from the Fondazione Cassa Risparmio di Modena and the Italian University Ministry is gratefully acknowledged.

${ }^{\dagger}$ University of Siegen and CESifo

$\ddagger$ University of Modena and Reggio Emilia and IZA. Corresponding author. Address: Department of Economics, University of Modena and Reggio Emilia, Viale J. Berengario 51, 41121 Modena (Italy), Tel. +39059 2056850, Fax +39059 2056947, Email: chiara.strozzi@unimore.it 


\section{Introduction}

Governments can regionally differentiate their policies along several dimensions. One important dimension is the regional differentiation of public employment, which can give rise to a critical equity-efficiency tradeoff. Alesina et al. (2001) document the regional differences in public employment in Italy. They show that these differences generate substantial redistributive effects and point out the associated efficiency costs due to an inter-regionally inefficient allocation of publicly provided goods and services, or due to detrimental productivity effects of a bloated public sector. Such findings raise the question whether regionally differentiated public employment is an appropriate redistributive instrument, and whether it is possible to characterize the inherent equity-efficiency trade-off of such a policy.

The potential role of public employment for efficient redistribution has originally been addressed by Wilson (1982). He uses a framework of optimal linear taxation and studies whether the public sector should alter the composition of its workforce in favor of high or low-skilled individuals. As he shows, the optimal policy involves a distortion of the public workforce composition, but its direction depends crucially on whether human capital formation is endogenous or not. Nichols and Zeckhauser (1982), Blumkin et al. (2009), and Blomquist et al. (2010), among others, have subsequently analyzed how government expenditures and regulation can potentially improve the efficiency of the tax-transfer system. None of these contributions, however, considers the regional policy dimension, which is the focus of our analysis. Only de la Fuente (2004) studies regionally differentiated policies as instruments of a second-best redistribution policy, but he focusses on investment. ${ }^{1}$

We develop an optimal taxation framework to study the equity-efficiency trade-off inherent in the regional differentiation of public employment. Our analysis shows that a regionally differentiated employment policy can be used as an expenditure side tagging device. Akerlof (1978) was the first to point out that the correlation of earnings ability with observable personal characteristics ("tags") can improve the efficiency of tax-transfer schemes. However, for reasons of horizontal equity, or of practical and political feasibility, such tags are typically not applied in real world tax systems (see Boadway and Pestieau (2006)). This is also true for the regional dimension, since income taxes set by central governments are typically not differentiated by region. We argue that public employment

\footnotetext{
${ }^{1}$ There is also a political economy and bureaucracy literature, where public employment is seen as an instrument for politicians to channel rents to specific groups either to generate political support (Gelb et al. (1991), López-de-Silanes et al. (1989)), to disguise the amount of transfers channeled to some favored minority group (Alesina et al. (2000)), or to create commitment within a bureaucracy (Kessing and Konrad (2008)).
} 
can be an expenditure side substitute that also allows the tagging of low productivity individuals, and we identify several channels how regionally differentiated public employment may improve efficiency. First, public employment generates goods and services which are consumed locally. Higher public employment in low productivity regions thus generates a direct targeted consumption effect, without violating incentive compatibility. This channel works identically for regionally differentiated government spending. Second, because public sector productivity tends to be less regionally dispersed than private sector productivity, the opportunity costs of moving a worker from the private to the public sector tends to be lower in low productivity regions. Finally, a regional differentiation of public employment eases incentive compatibility, if regional private sector wages depend on regional public employment.

Most existing empirical studies on the determinants of public employment, such as Rodrik (2000), and Martínez-Vázquez and Ming-Hung (2009), consider data at the country level, so they do not provide any evidence regarding the regional distribution of public employment. A few studies have already considered the regional dimension of public employment for specific countries. Jaimovich and Rud (2009), for example, analyze the regional evolution of public employment from a political economy perspective, with a focus on Argentina. Alesina et al. (2001) study regional public employment in Italy, whereas Borge and Matsen (2004) consider the role of public employment for risk sharing at the regional level in Norway.

In our empirical analysis we go beyond individual country-level approaches and explicitly consider a cross-country dimension. Our aim is to detect regularities in the regional patterns of public employment across countries and to explore the possibility that such patterns are systematically correlated with the degree of regional inequality. We assess the regional pattern of public employment in Europe using an hitherto unexploited panel data set of regional public employment. Our findings indicate that public employment is significantly higher in low productivity regions and that this relationship is more pronounced in countries with higher degrees of regional inequality.

\section{Theoretical framework}

\section{$2.1 \quad$ A baseline model}

We consider an optimal direct taxation model in the Stiglitz (1982) tradition. There are two regions $i=1,2$, with their respective population normalized to one, and two types of individuals $j=L, H$. The types differ in their productivity such that we have $w_{H}>w_{L}$, where $w_{H}$ is the wage of high productivity individuals and $w_{L}$ is the wage of 
low productivity individuals. The share of individuals of type $j$ in region $i$ is $m_{i j}$. Region 2 has a higher productivity on average than region 1 , so that $1 \geq m_{2 H}>m_{1 H} \geq 0$. As usual in the optimal taxation approach, all individuals have the same preferences, which are given by a simple quasi-linear specification

$$
U_{i j}=x_{i j}-h\left(l_{i j}\right)+v\left(g_{i}\right),
$$

with $h^{\prime}(l)>0, h^{\prime \prime}(l)>0, v^{\prime}(g)>0, v^{\prime \prime}(g)<0$, where $x_{i j}$ is private good consumption, $l_{i j}$ is individual labor supply, $h\left(l_{i j}\right)$ the disutility of labor, and $g_{i}$ is a locally consumed public good. We interpret the latter as public employment, implicitly assuming a public sector with a linear technology. ${ }^{2}$ The prices of private and public goods are normalized to one.

Society is inequality averse. We employ a CES-type social welfare function

$$
W=\sum_{i=1,2} \sum_{j=L, H} m_{i j} \frac{U_{i j}^{\rho}}{\rho}, \text { with } 0 \neq \rho<1,
$$

as in Blumkin et al. (2009), where the parameter $\rho$ is a measure of inequality aversion. ${ }^{3}$ The government implements a tax system that defines taxes $T_{j}=T\left(w_{j} l_{j}\right)$ as a function of gross income only. The government cannot condition the tax system on the region of residence in line with the empirical evidence. Taxes determine net income and private consumption, $x_{j}=w_{j} l_{j}-T\left(w_{j} l_{j}\right)$. Since the government cannot directly observe individuals' productivity and conditions taxes on gross income, the tax system needs to be incentive compatible. We only consider the downward incentive compatibility constraint

$$
x_{H}-h\left(l_{H}\right) \geq x_{L}-h(\hat{l})
$$

where the hat on a variable indicates a high productivity individual mimicking a low productivity individual, such that $\hat{l}=\frac{w_{L}}{w_{H}} l_{L}$. Public employment does not enter the incentive compatibility constraint since both types of workers consume the public goods provided in their region. Finally, taxes redistribute and finance public employment. To facilitate comparative statics, we assume an exogenous average level of public employment $g$ and assume that $g_{1}=(1+a) g$ and $g_{2}=(1-a) g$, so that the parameter $a \in[-1,1]$

\footnotetext{
${ }^{2}$ Alternatively, the regionally provided goods $g_{i}$ could be produced privately and could only be purchased by the public sector. This implies that the analysis of this section also applies to the regional distribution of public spending.

${ }^{3}$ As $\rho \rightarrow 1$ we approach the Utilitarian case, and as $\rho \rightarrow-\infty$ we approach the Rawlsian case. Here, given that individual preferences are linear in consumption, inequality aversion is a necessary condition for the desirability of redistribution, and, accordingly, also for public employment to potentially increase the efficiency of redistribution.
} 
summarizes regional differentiation. The government's budget constraint is

$$
\left(m_{1 H}+m_{2 H}\right)\left(w_{H} l_{H}-x_{H}\right)+\left(m_{1 L}+m_{2 L}\right)\left(w_{L} l_{L}-x_{L}\right) \geq 2 g .
$$

The government maximizes (2) subject to (3) and (4). Solving (3) and (4) for $x_{L}$ and $x_{H}$, and substituting into (2), it maximizes (2) by choosing $l_{L}, l_{H}$, and $a$. The first order condition with respect to $a$ is

$$
\left[m_{1 L} U_{1 L}^{\rho-1}+m_{1 H} U_{1 H}^{\rho-1}\right] v^{\prime}\left(g_{1}\right)=\left[m_{2 L} U_{2 L}^{\rho-1}+m_{2 H} U_{2 H}^{\rho-1}\right] v^{\prime}\left(g_{2}\right)
$$

The optimal solution thus requires $v^{\prime}\left(g_{1}^{*}\right)<v^{\prime}\left(g_{2}^{*}\right)$ and therefore $g_{1}^{*}>g_{2}^{*}$ and $a^{*}>0$, where the asterisks indicate optimal values. We summarize this in Proposition 1.

Proposition 1 If regions differ in their average productivity and the government cannot observe individual productivity, social welfare maximization will entail $a^{*}>0$.

Optimal public employment should be higher in the low productivity region. Intuitively, since the locally consumed public goods provided through public employment do not enter the incentive compatibility constraint (3), they can be used for redistribution. The optimum trades off the welfare gains from redistribution with the costs of distorted public goods supply. Our next proposition addresses the degree of regional inequality.

Proposition 2 An increase in productivity differences across regions, keeping the total share of high and low productivity individuals constant, increases the optimal degree of regional differentiation of public employment.

Proof. See Kessing and Strozzi (2012).

If regional productivity differences are more pronounced, the optimal policy requires a stronger differentiation. Intuitively, with more regional inequality, public employment becomes a better targeted instrument for redistribution.

\subsection{Endogenous wages and public sector production}

Alesina et al. (2001) stress the double role of public employment. Besides the consumption of regionally differentiated levels of public goods and services, there are also important effects on regional labor markets. These originate from public labor demand, which can drive up regional private sector wages. Additionally, optimal public employment should take into account the specific structure of public sector production which typically exhibits lower regional variation in productivity relative to the private sector. In order to study 
these aspects we now model employment and production in the public sector explicitly and allow for endogenous wages.

We concentrate on the case of perfect correlation between individual productivity and the place of residence, by setting $m_{1 L}=m_{2 H}=1$ and $m_{1 H}=m_{2 L}=0$, such that we can drop the subscripts $L$ and $H$. This perfect correlation assumption is for expositional clarity. The government's objective simplifies to $W=\sum_{i=1,2} \frac{U_{i}^{\rho}}{\rho}$. We again assume that the government knows the regional productivity shares but is not allowed to condition the tax schedule on the region of residence. ${ }^{4}$

Individuals either work in the private or in the public sector. We denote the fraction of individuals in the public sector by $n_{i}$, such that $1-n_{i}$ work in the private sector. Private good production $q_{i}$ is determined by a regional production function $f_{i}(),. f_{i}^{\prime}()>$.0 , $f_{i}^{\prime \prime}()<$.0 , while total labor input in the private sector is given as the share of private sector workers times their individual labor supply

$$
q_{i}=f_{i}\left(l_{i}\left(1-n_{i}\right)\right)
$$

This implies the existence of pure profits. As in related studies, such as Blackorby and Brett (2004), these are assumed to be fully taxed. The publicly provided good $g_{i}$ is locally produced according to the linear relationship

$$
g_{i}=n_{i} l_{i}
$$

Labor is equally productive in the public sector in both regions with a constant marginal productivity. This is a useful benchmark given that regional productivity dispersion is typically smaller in the public sector. Private production can be expressed as $q_{i}=f_{i}\left(l_{i}-g_{i}\right)$. Region 2 is the more productive region, which we capture by a higher marginal labor productivity. Assuming labor is paid its private sector marginal product, the productivity difference between regions is

$$
w_{2}=f_{2}^{\prime}\left(l_{2}-g_{2}\right)>f_{1}^{\prime}\left(l_{1}-g_{1}\right)=w_{1}
$$

We assume that the public and the private sector pay the same wage in each region, and there is again no migration. Given these assumptions, an increase in regional public labor demand reduces private employment, which increases the marginal product of labor and

\footnotetext{
${ }^{4}$ With perfect correlation, allowing the government to condition taxation on residence would enable it to implement the first best. Moreover, if the government itself did not know which region was the high or the low productivity region, the incentive compatibility constraint would have to be adjusted.
} 
regional wages. We define the inter-regional wage ratio as

$$
z \equiv \frac{w_{1}}{w_{2}}=\frac{f_{1}^{\prime}\left(l_{1}-g_{1}\right)}{f_{2}^{\prime}\left(l_{2}-g_{2}\right)}
$$

The wage ratio is increasing in the public good production in region $1, \frac{\partial z}{\partial g_{1}}>0$, but decreasing in public good production in region $2, \frac{\partial z}{\partial g_{2}}<0$. The government's constraints are now the incentive compatibility constraint

$$
x_{2}-h\left(l_{2}\right) \geq x_{1}-h\left(z l_{1}\right),
$$

and the aggregate resource constraint

$$
x_{1}+x_{2} \leq f_{1}\left(l_{1}-g_{1}\right)+f_{2}\left(l_{2}-g_{2}\right),
$$

which implies the government's budget constraint. Again assuming a total production of $2 g$, we focus on the differentiation parameter $a$, where $g_{1}=(1+a) g$ and $g_{2}=(1-a) g$. The government maximizes the simplified version of (2) by choice of $x_{1}, x_{2}, l_{1}, l_{2}, a$ subject to (10) and (11). Optimality requires the first order condition with respect to $a$

$$
U_{2}^{\rho-1} v^{\prime}\left(g_{2}\right)-U_{1}^{\rho-1} v^{\prime}\left(g_{1}\right)=\lambda l_{1} h^{\prime}(\hat{l})\left[\frac{\partial z}{\partial g_{1}}-\frac{\partial z}{\partial g_{2}}\right]+\mu\left[f_{2}^{\prime}\left(l_{2}-g_{2}\right)-f_{1}^{\prime}\left(l_{1}-g_{1}\right)\right]
$$

where $\lambda$ and $\mu$ denote the Lagrange multipliers corresponding to (10) and (11), respectively. From this we derive our next proposition.

Proposition 3 With endogenous wages the optimal policy requires public employment and public goods production to be higher in the region with lower average productivity: $n_{1}^{*}>n_{2}^{*}, g_{1}^{*}>g_{2}^{*}$, and $a^{*}>0$.

Proof. See Kessing and Strozzi (2012).

Comparing (5) with (12) indicates two additional reasons for regional differentiation. First, while productivity in the public sector is the same in both regions, opportunity costs are different. This is evident from the second term on the RHS of (12), which is the regional difference in marginal productivity, valued at the society's shadow value of additional private goods.

The second effect relates to the role of regionally differentiated public employment for efficient redistribution. It is embodied in the first term on the right hand side of (12), $\lambda \hat{u}_{l}^{2}\left[\frac{\partial z}{\partial g_{1}}-\frac{\partial z}{\partial g_{2}}\right]$. This effect is also positive. Increasing public employment in the low productivity region and decreasing it in the high productivity region reduces the 
wage differential. This effect makes it less attractive for high income earners to mimic low income workers. Thus, regionally differentiated public employment relaxes incentive compatibility.

Finally, one can again ask how, in the case of endogenous wages, optimal regional differentiation of public employment changes as the degree of regional inequality changes. Using further functional assumptions about regional productivity differences, one can show that a combination of an Inada-type condition on the production function and a sufficiently high level of average public employment is sufficient to derive a result paralleling Proposition 2. This is intuitive, since, the higher the average provision level, the stronger are the marginal effects of differentiation of this level on wages and redistribution.

\subsection{Extensions}

Our theoretical analysis has deliberately abstracted from a number of aspects that are potentially relevant.

Inequality aversion. More inequality averse policy makers will unambiguously favor more redistribution for given efficiency costs. As the scope of redistribution increases, so does the possibility of using public employment as an expenditure side tagging device.

Public sector wage premia. Public sector wage premia would introduce an additional inefficiency into production, would increase the utility of public sector workers and could put upward pressure on private sector wages (as private firms may be forced to increase wages. Overall, they should reduce the level of public employment, but their effect on its regional distribution is not evident.

Regional differences in unemployment. Moving workers out of unemployment into public employment implies lower opportunity costs than moving a worker from the private to the public sector. On the other hand, with slack in the labor market, the positive effect on private sector wages and the resulting effects on incentive compatibility are dampened.

Regional and local governments. Subnational governments play an important role for public employment. However, they usually depend on financing from the central government. Accordingly, the central government has more options to regionally differentiate its policy. The lower level governments typically only have the discretion to decide whether to spend their revenue directly, or whether to use it for public employment. Thus, differentiated grants may also be interpreted as similar expenditure side tagging devices to complement the redistributive tax system.

Migration. With heterogenous migration costs, for the non-marginal individuals, the efficiency gains from tagging are still present. With costly mobility there will thus be a 
trade-off between tagging using regionally differentiated policies to improve the efficiency of redistribution and the desire to increase migration from the low to the high productivity region.

Organized crime. In countries with weaker governance regional policies can be affected by the presence of organized crime (see Pinotti (2015) for the case of Italy, for example). The presence of organized crime can affect regional productivity, and public investment may be used to substitute a lack of private activity in affected regions. However, low efficiency of public investment may also make public employment relatively more attractive as an instrument for redistribution.

\section{Empirical analysis}

\subsection{Data}

To empirically investigate the link between regional public employment per capita and regional productivity in Europe, we assemble a data set with regional data at NUTS 2 level for 17 European countries. ${ }^{5}$ All regional data are taken from Eurostat regional statistics and range from 1995 to 2007. For all details about data and sources, see the Appendix.

Our main measure of public employment is the number of people employed in the NACE sector "Public administration and defence; compulsory social security". We consider this measure although it does not include public employment in sectors such as education and health care. This choice is mainly due to the fact that the Eurostat Labour Force Survey (LFS) data does not allow to distinguish private and public sector workers in these sectors, where private firms or non-profit organizations play an important role, and this role may vary substantially across regions and countries. Our measure does include, however, some important locally provided public services such as the police and fire-fighters. From a consumption perspective, this implies that this measure partly captures services that predominantly benefit the local population, but also includes public goods and services, such as defense, that accrue to the entire population. While our measure does not include the entire public sector, it is consistent across regions and countries. Since our focus is the regional distribution of public employment from a cross-country perspective and not the overall size of the public sector, a narrower but consistent measure of public employment is more useful than a broader measure with regional and/or cross-country inconsistencies. However, for robustness, we also consider a

\footnotetext{
${ }^{5}$ The countries are: Austria, Belgium, Czech Republic, Finland, France, Germany, Greece, Hungary, Italy, Netherlands, Poland, Portugal, Romania, Spain, Sweden, Slovak Republic, United Kingdom.
} 


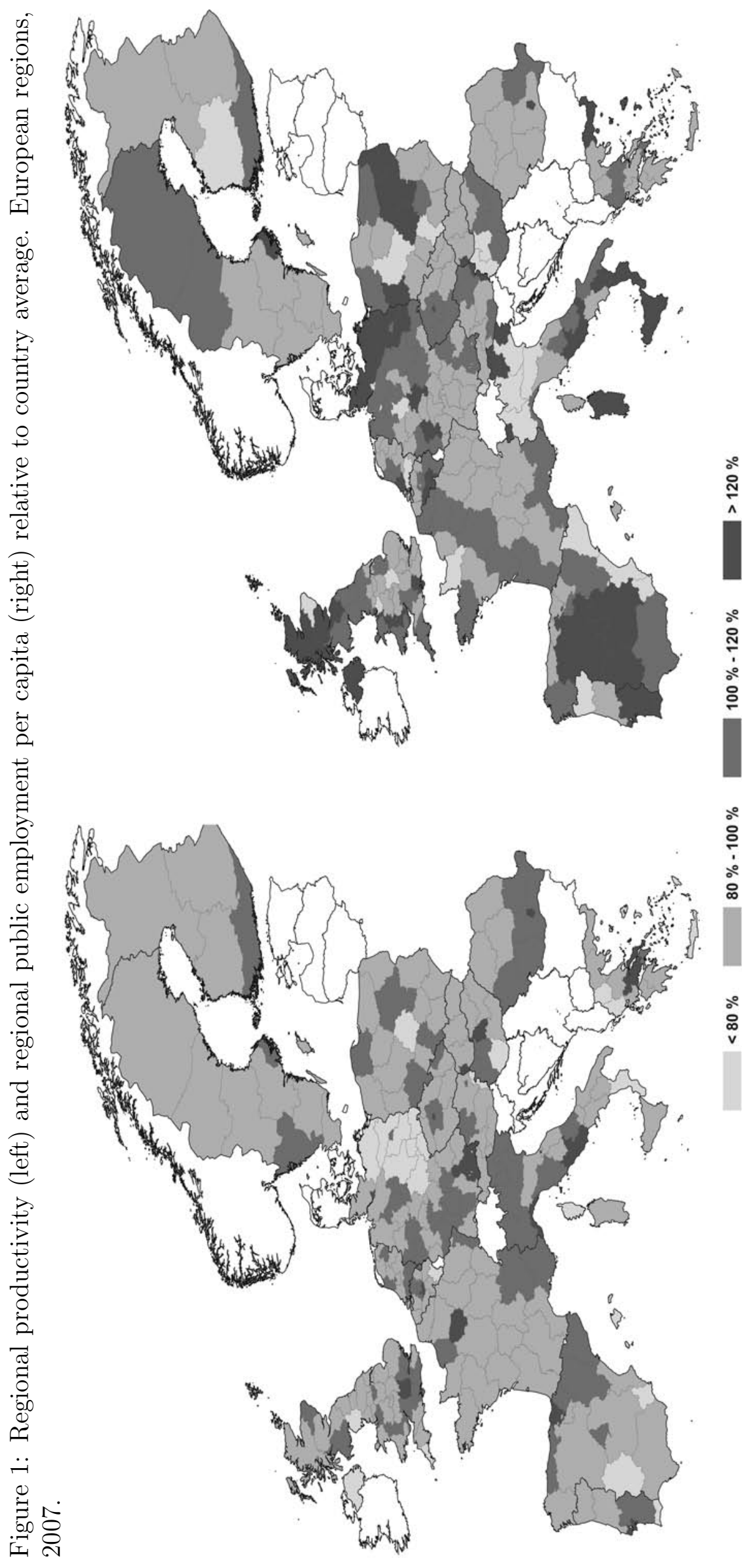


Figure 2: Relative regional productivity and relative regional public employment per capita in the six biggest European countries, 2007.
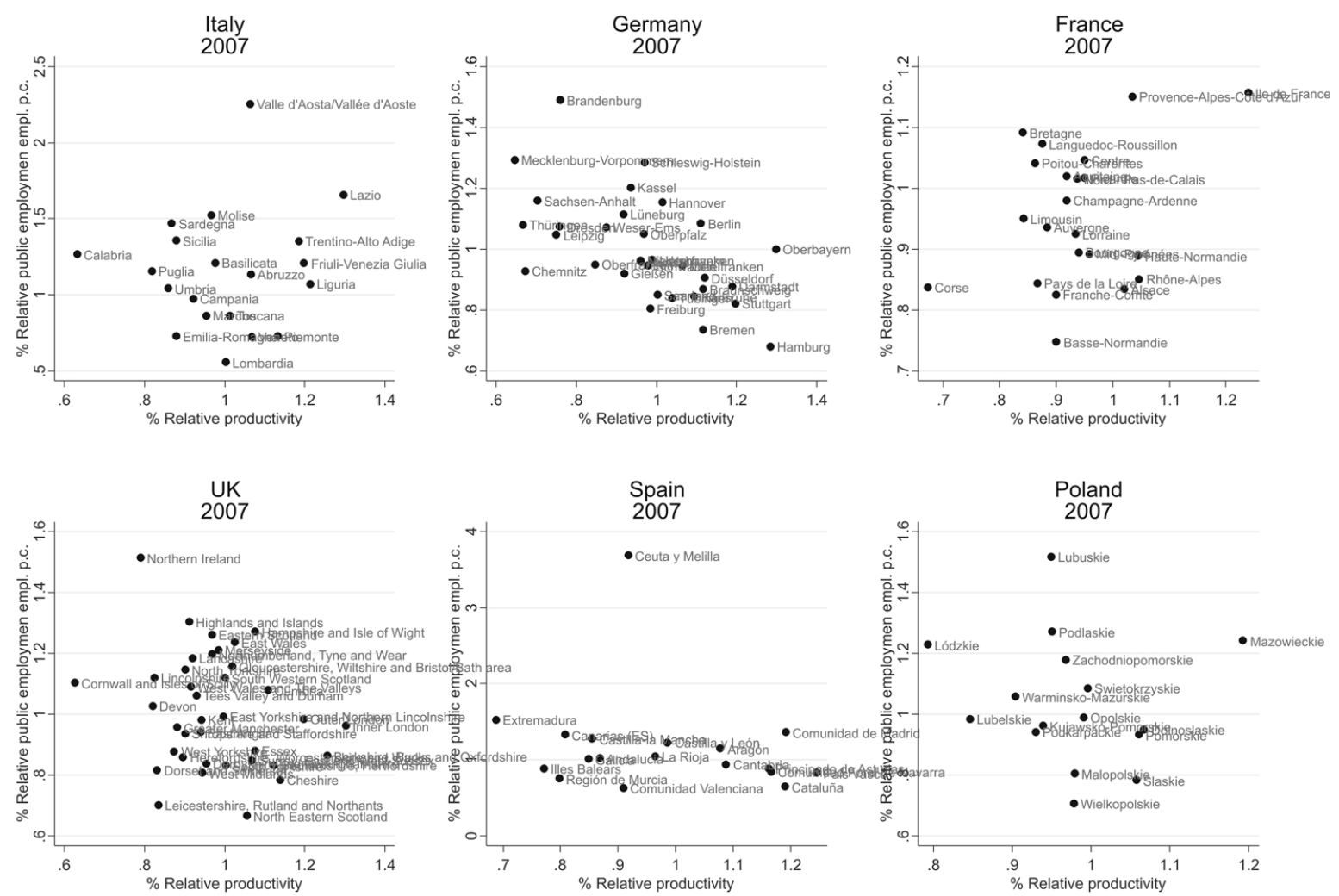

more comprehensive measure of public employment which additionally includes the health and education sectors. As productivity measure we adopt regional wages and salaries per number of employed persons in manufacturing.

Preliminary evidence of the link between regional public employment per capita and regional productivity is presented in Figure 1. The figure shows two maps of $243 \mathrm{Eu}-$ ropean regions classified according to their regional productivity per worker (left) and regional public employment per capita (right) with respect to their country average in 2007. To calculate the country averages, each regional measure has been weighted by the population share of the corresponding region. Regions have been grouped into four categories according to their relative position with respect to their country average: $<80 \%$, $80-100 \%, 100-120 \%$ and $>120 \%$. The maps show that there is substantial dispersion of relative regional productivity and relative regional public employment. In addition, in some countries there is evidence of a correspondence between a relatively low level of productivity and a relatively high level of public employment (e.g. Italy and Germany). The scatter-plots presented in Figure 2 illustrate the correlation between regional relative productivity and regional relative public employment per capita in the six biggest European countries in terms of population in 2007. A negative relationship between these 
variables appears to be visible for most of the countries, while not for all of them (e.g. France).

The figure also illustrates the unambiguously high level of relative public employment per capita in the capital regions of our sample (e.g. Lazio and Ile de France) and in some other regions (e.g. Ceuta y Melilla). In line with this evidence we exclude outlier regions from the initial sample and our further analysis uses 221 regions. ${ }^{6}$ The summary statistics of the variables included in the final sample are presented in Table 1. They show that in our sample, according to our definition of public employment per capita which only includes public employment in public administration ("Public employment"), on average $3 \%$ of the population work in the public sector. The more comprehensive employment measure including employment in education and health sectors ("Public employment (edu-health)") shows that on average $10 \%$ of the population work in the public sector. Moreover, the average relative public to private compensation is 1.134 , evidencing the presence of public sector wage premia.

Table 1: Summary statistics

\begin{tabular}{rccccc}
\hline Variable & Obs & Mean & Std.Dev. & Min & Max \\
\hline Public employment & 2668 & 0.031 & 0.009 & 0.008 & 0.073 \\
Public employment (edu-health) & 2671 & 0.100 & 0.028 & 0.035 & 0.210 \\
Productivity & 2303 & 0.023 & 0.010 & 0.001 & 0.050 \\
Inequality & 2410 & 0.135 & 0.040 & 0.014 & 0.254 \\
GDP per capita & 2671 & 19246 & 6504 & 3400 & 47800 \\
Population density & 2415 & 0.250 & 0.425 & 0.003 & 3.656 \\
Dependency ratio & 2675 & 0.505 & 0.048 & 0.374 & 0.627 \\
Relative compensation & 2386 & 1.136 & 0.277 & 0.841 & 2.192 \\
Unemployment rate & 2676 & 0.089 & 0.052 & 0.012 & 0.334 \\
Fiscal decentralization & 2613 & 0.131 & 0.106 & 0.008 & 0.332 \\
Fiscal decentralization (alt.) & 2495 & 0.183 & 0.101 & 0.015 & 0.368 \\
HRST as a \% of active pop. & 2570 & 0.312 & 0.083 & 0.095 & 0.601 \\
Patent applications & 1777 & 106.694 & 126.352 & 0.018 & 1018.304 \\
\hline & & & & &
\end{tabular}

\subsection{Empirical specification}

Our theoretical framework implied that i) regions with lower productivity should have higher levels of public employment and ii) the negative correlation between regional public employment and regional productivity should be more pronounced in countries with higher regional inequality. We adopt an empirical specification which uses the nested

\footnotetext{
${ }^{6}$ From the initial sample of 243 regions we take out all the 17 capital regions. In the Netherlands we exclude South Holland instead of North Holland since The Hague and not Amsterdam is the administrative capital. In addition, we eliminate Ceuta-y-Melilla and Northern Ireland due to the large presence of security personnel (see also Figure 2). We also take out the three Atlantic islands of the sample (Canarias, Madeira, and Açores) in line with the standard practice of empirical studies on European regions. A sensitivity analysis shows that our results do not hinge on these exclusions. See also Section 4.3 for the capital regions.
} 
structure of regions within the European countries, and focus on three key variables: public employment per capita, productivity and the degree of regional inequality. The reference empirical specification is

$$
\text { publempl }_{i k t}=\beta_{0}+\beta_{1} \operatorname{prod}_{i k t}+\beta_{2} i_{n e q}+\beta_{3} \operatorname{prod}_{i k t} i n e q_{k t}+\beta_{4} Z_{i k t}+z_{i}+x_{t}+\varepsilon_{i k t},
$$

with $i$ indicating region, $k$ indicating country and $t$ indicating time (year). The unit of analysis is a region-country-year.

The dependent variable publempl $_{i k t}$ is public employment per capita. The three main variables of interest are: productivity $\left(\operatorname{prod}_{i k t}\right)$, inequality $\left(\operatorname{ineq}_{k t}\right)$ and the interaction term between productivity and inequality $\left(\operatorname{prod}_{i k t} i n e q_{k t}\right)$. While productivity and public employment per capita are measured at regional level, the degree of regional inequality is evaluated at country level, and is measured by the coefficient of variation. ${ }^{7}$ The cumulative effect of productivity on public employment per capita is then captured by $\beta_{1}$ and $\beta_{3} i n e q_{k t}$, and varies with the degree of regional inequality within the country. The vector $Z_{i k t}$ is a vector of additional control variables at regional level: among them we include population density, to account for size effects, and its squared term, to account for a possibly non-linear impact of it. A further regional-level control is the dependency ratio. To account for the potential role of public sector wage premia and of regional unemployment differentials, we include as controls the ratio of public to private compensation and the regional unemployment rate, together with its squared term. We also control for the degree of fiscal decentralization. ${ }^{8}$ Finally, the $z_{i}$ are time-invariant region-specific characteristics, $x_{t}$ are time fixed effects and $\varepsilon_{i k t}$ is the error term.

\section{Results}

\subsection{Baseline results}

Table 2 presents the results of nine different empirical specifications. All specifications are panel data regressions: while Columns (1)-(8) include region-fixed effects, Column (9) provides a random effects specification. ${ }^{9}$ The dependent variable is public employment

\footnotetext{
${ }^{7}$ The coefficient of variation is conceptually independent of the country size, but can be affected by average region size. Ceteris paribus, if a country is characterized by smaller regions on average, this should result in a higher coefficient of variation. However, NUTS 2 regions have a predetermined average population range between 800,000 and 3,000,000 people. Moreover, in our sample the coefficient of variation shows to be positively correlated with average region size at the country level.

${ }^{8}$ For lack of relevant data at regional level, relative public to private compensation is measured only at country level, as is fiscal decentralization, given the nature of this variable.

${ }^{9}$ The corresponding pooled OLS regressions are in the Appendix. F-test results show that the null hypothesis of no fixed effects is strongly rejected with $\mathrm{F}$ statistics around or above 30. It is also worth
} 
per capita. Column (1) includes only productivity, Column (2) adds inequality, Column (3) includes our key regressor, i.e. the interaction term between regional productivity and inequality. The results in Column (3) show that while productivity is insignificant, inequality is positive and strongly significant and the interaction term is negative and strongly significant. These findings are in line with the implications of our theoretical framework: the negative relationship between productivity and public employment is more pronounced in countries with higher degrees of regional inequality. In addition, country-level regional inequality goes along with higher public employment.

Column (4) adds to the specification of Column (3) two key control variables: the dependency ratio and population density. The population density is insignificant, which may be explained by its low variation over time. The dependency ratio is negative and significant. The latter finding may be due to the nature of the public employment measure, which does not include employment in the education and health care sectors. Moreover, once we focus on the differences over time within regions, we must consider that a decrease in working age population (as the denominator of the dependency ratio) should have ceteris paribus a negative effect on both public and private employment. Column (5) of Table 2 includes squared population density, which is positive but only becomes significant when we add further explanatory variables. Column (6) adds to the previous regressors public to private relative compensation and the regional unemployment rate, while Column (7) adds the squared unemployment rate. Relative compensation is negative and significant, as expected. Moreover, there is some evidence that there is a non-linear relationship between unemployment and public employment with a negative effect of the unemployment rate, but a positive effect of its squared term. Given the range of unemployment rates in our regions, the combined effect is always negative, however. Column (8) adds to Column (7) our measure of fiscal decentralization: this column represents our full specification. As a measure of fiscal decentralization we consider the ratio of the sum of local and regional tax revenues to total government tax revenues. As it appears from Column (8), fiscal decentralization is positive and significant, which is in line with Martinez-Vazquez and Ming-Hung (2009). Again, the interaction term between productivity and inequality maintains its sign and significance level: the full specification hence indicates that our key findings are robust to the inclusion of a range of relevant control variables. Finally, the random effects estimates of our full specification in Column (9) confirm our fixed effects results. Since a Hausman test reveals that the fixed effects approach is superior to the random effects approach, Column (8) is our reference

pointing out that these regression results cannot be interpreted strictly in a causal way. However, they are relevant to uncover some meaningful correlations among the variables of interest. Endogeneity issues are considered in Section 4.3 . 


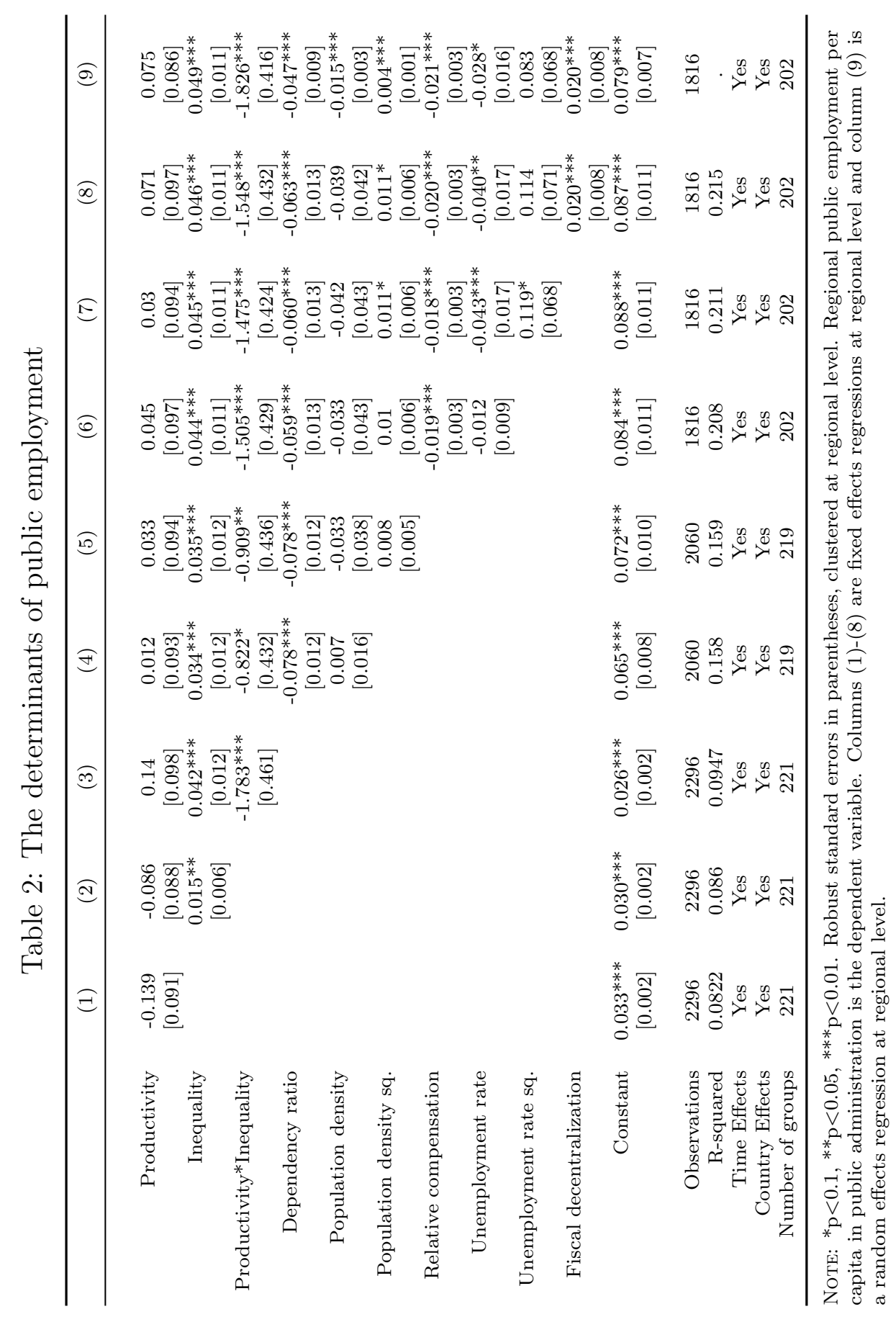


specification. ${ }^{10}$

Next, we consider how the total effect of productivity on public employment is influenced by a country's degree of inequality. Figure 3 illustrates the total marginal effect of productivity as a function of regional inequality according to our reference specification. The total effect of productivity on public employment is significantly negative above a certain degree of inequality (about 0.15 ).

Figure 3: Total effect of productivity according to the degree of inequality

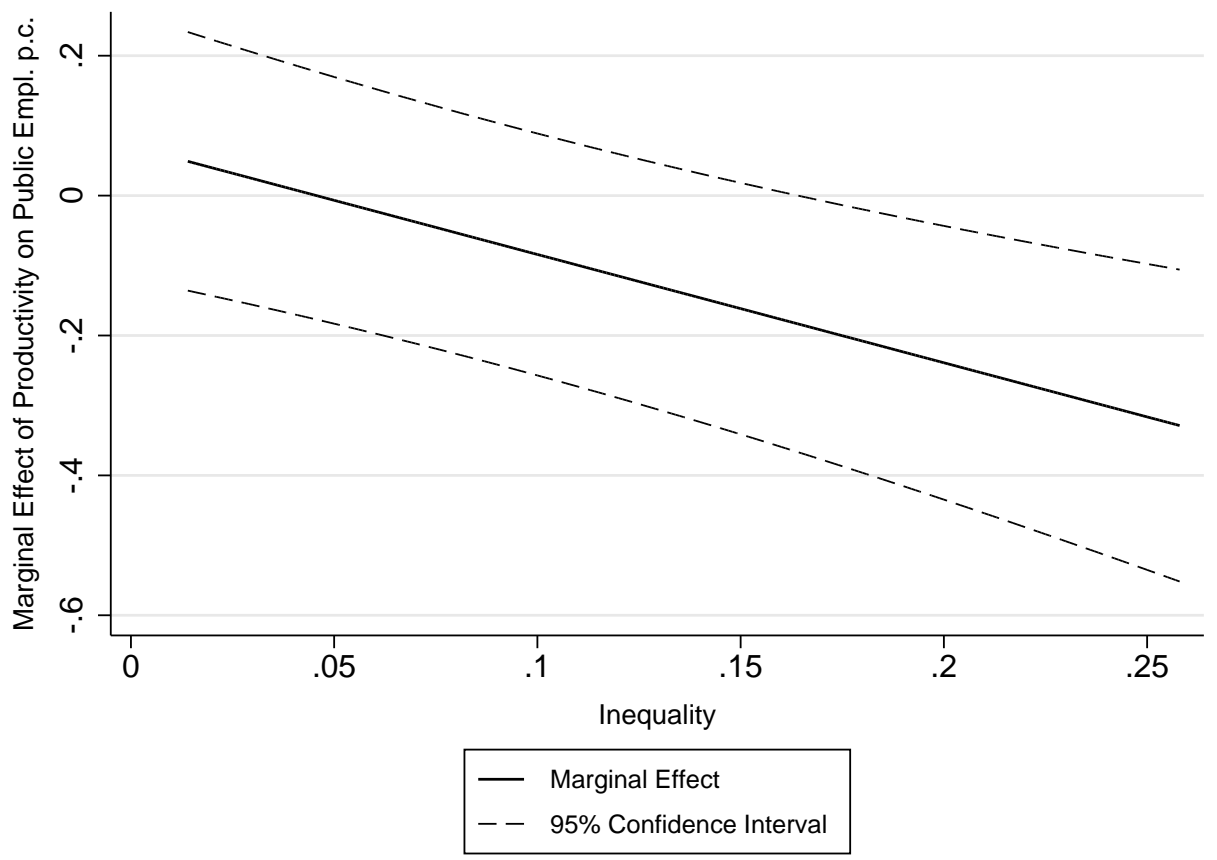

Note: The graph refers to the estimates of our reference regression in Column (8) of Table 2. The total effect of productivity on public employment includes the direct effect of productivity and the effect depending on the degree of inequality.

From a quantitative perspective, the average marginal effect of a productivity increase as measured by an increase in the average salary of a worker in the manufacturing sector by 1000 Euros, corresponds to a decrease of regional public employment by $0.45 \%$. This average effect hides the heterogeneity of countries. Consider Finland and Italy with a low and a high degree of inequality, respectively. Finland has an average degree of inequality (as measured by the coefficient of variation in our sample) equal to 0.037, while for Italy this measure has a value of 0.171 . Average public employment per 100 inhabitants is about 3.2 in Italy and about 2.2 in Finland. Our results imply that an increase in regional productivity, again measured by an increase in the average salary of a worker in the manufacturing sector by 1000 Euros, corresponds to a decrease in regional public

\footnotetext{
${ }^{10}$ The Hausman test compares the model in column (8) with the model in column (9) of Table 2. The results show that null hypothesis is rejected and thus that our preferred model is the fixed effects model. The relevant Chi-squared statistics is Chi2(11) $=40.31$.
} 
employment per capita of $0.6 \%$ in Italy, while it corresponds to an increase in Finland (even if, however, only of $0.063 \%$ of public employment).

\subsection{The role of additional factors}

We now consider in more detail the role of additional factors that can influence the link between productivity, inequality, and public employment. We first focus on inequality aversion. Conceptually, we derived the prediction that higher levels of inequality aversion should result in stronger regional differentiation of public employment. ${ }^{11}$ To define inequality aversion we choose a measure which is constructed from the 2009 International Social Survey Programme (ISSP) "Social Inequality IV", which includes opinion data in 14 out of the 17 countries of our original sample: Austria, Belgium, Finland, France, Germany, Hungary, Italy, Poland, Portugal, Slovak Republic, Spain, Sweden, United Kingdom. We focus on the respondents' degree of agreement with the statement "It is the responsibility of the government to reduce the differences in income between people with high incomes and those with low incomes", which captures individual attitudes towards government redistribution. ${ }^{12}$

There are five possible degrees of agreement to the above statement: "Strongly agree", "Agree", "Neither agree nor disagree", "Disagree" and "Strongly disagree". We retrieved for each country the combined percentage of "Strongly agree" and "Agree" answers. After computing the average across countries of this combined percentage, we then define a dummy equal to 1 if in a certain country this combined percentage was equal or above the average and equal to 0 otherwise.

In Column (1) and (2) of Table 3 we replicate our reference regression of Column (8) of Table 2 for the countries that are less inequality averse (Column (1)) and for the inequality averse countries (Column (2)). The negative relationship between regional productivity and public employment is stronger for inequality averse countries, as predicted. These findings may be regarded as additional evidence that regionally differentiated public employment may indeed be used for redistributive purposes.

Following the discussion in Section 2.3, we also investigate empirically the role of additional aspects that could be relevant for the pattern of the regional distribution of public employment. We consider the role of public sector wage premia, unemployment dispersion, fiscal decentralization, migration, and crime. As we stressed in Section 2.3,

\footnotetext{
${ }^{11}$ See Footnote 3 and Section 2.3.

${ }^{12}$ This question has also been included in the 1999 ISSP "Social Inequality III". The correlation between the answer shares in the 1999 survey and the 2009 survey is about, or more than, .90 for the countries of our sample which are included in both surveys. Accordingly, since the 1999 survey includes substantially less countries of our sample than the 2009 survey, we decided to take this latter survey as our reference.
} 


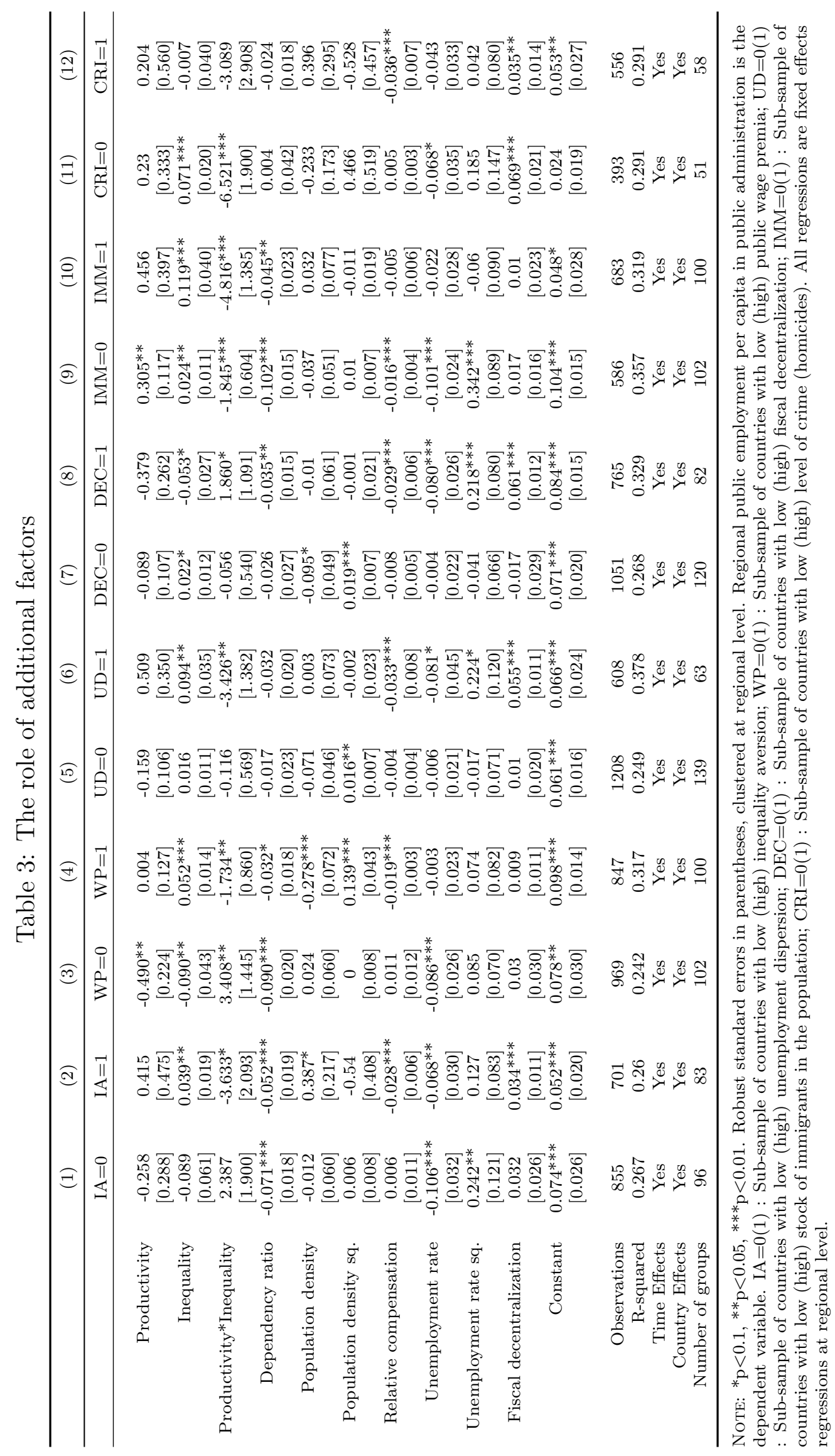


the effects of these factors on regional public employment are a priori ambiguous. Thus, we here perform an empirical analysis which is mainly explorative. Again, we split the countries into two respective groups of countries according to the following binary categories. We first divide them into countries with a positive and a negative public sector wage premia. Second, we consider countries with a high or a low regional dispersion of unemployment. Third, we consider whether fiscal decentralization is relatively high or not. Fourth, we distinguish countries with a high stock of international migrants as a percentage of the population from those with a low stock. Finally, we split the initial sample into countries with high or low crime rates. ${ }^{13}$ For each sub-sample of countries, we then run our full specification regression (see Table 3).

For countries with positive wage premia the results are similar to the full sample. However, with negative wage premia there is a negative direct effect of productivity and a positive interaction effect (see Columns (3) and (4)), indicating that negative wage premia reduce the attraction of public employment as a redistributive instrument in regionally more heterogeneous countries. Columns (5) and (6) correspond to countries with high and low unemployment dispersion, respectively. Only countries characterized by high unemployment dispersion show the pattern of higher regional public employment in regions with lower productivity. This may be driven by the higher tagging potential in such countries. Splitting the sample of countries in high and low fiscal decentralization countries generates less significant coefficients for our variables of interest (Columns (7) and (8)). While the total marginal effect of productivity, including the direct and the interaction effect, is still negative for both groups, the estimated coefficients are no longer significant. Next, given that no data on interregional migration are available, we use national-level data on international immigration to identify countries where migration is important. The extent of immigration can be regarded as a proxy for the migration frictions within a country. The results shown in Columns (9) and (10) indicate that the main results are robust for both groups, but that the interaction between inequality and productivity is more pronounced in high migration countries. Explanations for this finding could be a stronger perceived need for regional redistribution in these countries, or the correlation between immigration and more pronounced welfare states, where the latter also implies that there is more scope for targeted redistribution via regionally differentiated public employment. Finally, we analyze the role of crime. As a proxy for the prevalence of

\footnotetext{
${ }^{13}$ The thresholds are the mean values of the respective variables over the interval 1995-2007. For migration we use the stock of immigrant population as a share of total population from Eurostat's Migration and Migrant Population Statistics. For (organized) crime we use the number of homicides (per capita) from Eurostat statistics on "Crime and Criminal Justice". We additionally split the sample according to the median of the classification variable. The results (not reported) do not change much, with the exception of crime, where the differences between the high and low crime countries largely disappear. The results are available from the authors upon request.
} 
organized crime, we use the number of homicides per capita at the country level. As is evident from Columns (11) and (12), results are quite different for the two groups. We find strong effects for the low crime countries, in line with our baseline findings. However, for the high crime countries, the variables of interest are all insignificant, indicating that high crime levels can interfere with our baseline predictions.

\subsection{Robustness checks}

We next run some robustness checks in Table 4. Column (1) reports the estimates of our reference specification (i.e. Column (8) of Table 2) while the following columns report our robustness checks. In Column (2) we test the role of additional controls: we here focus on the share of skilled workers, since results of Proposition 2 are derived by assuming a constant share of skilled labor. The regression in Column (2) additionally includes our chosen measure of skilled labor: human resources in science and technology (HRST) as a share of the economically active population. The coefficients of our three main variables of interest (productivity, inequality and the interaction term between the two) have the same sign and significance as in our reference regression. In Column (3) we investigate an alternative fiscal decentralization measure, the share of local and regional government expenditure in total government expenditure. This alternative measure has the same sign as before and the significance of the coefficient is broadly similar. Column (4) tests an alternative dependent variable: we here consider a public employment measure which also includes employment in education and health sectors. The results show that that there are important differences compared to our reference regression of Column (1): productivity is positive and significant. The positive sign of the productivity coefficient may be explained by the high income elasticity of the goods and services provided by these sectors. This is relevant for public and private employment in these sectors; however, since this alternative measure aggregates private and public employment, we cannot identify whether this effect is more or less important in either sector, or whether the overall effect of productivity is entirely driven by the private component of our dependent variable. The total effect of productivity is now positive for all levels of inequality. However, this positive effect is less pronounced in countries that are regionally more unequal, indicating that the effect of higher public employment in more productive regions is reduced in these countries, in line with our theoretical argument.

In Table 4 we also address the potential endogeneity of regional productivity. Regional public employment can affect regional productivity due to a number of reasons. First, increased public employment may provide important inputs, such as security, swift contract enforcement, rule of law, etc. that increase private sector productivity. Second, as 


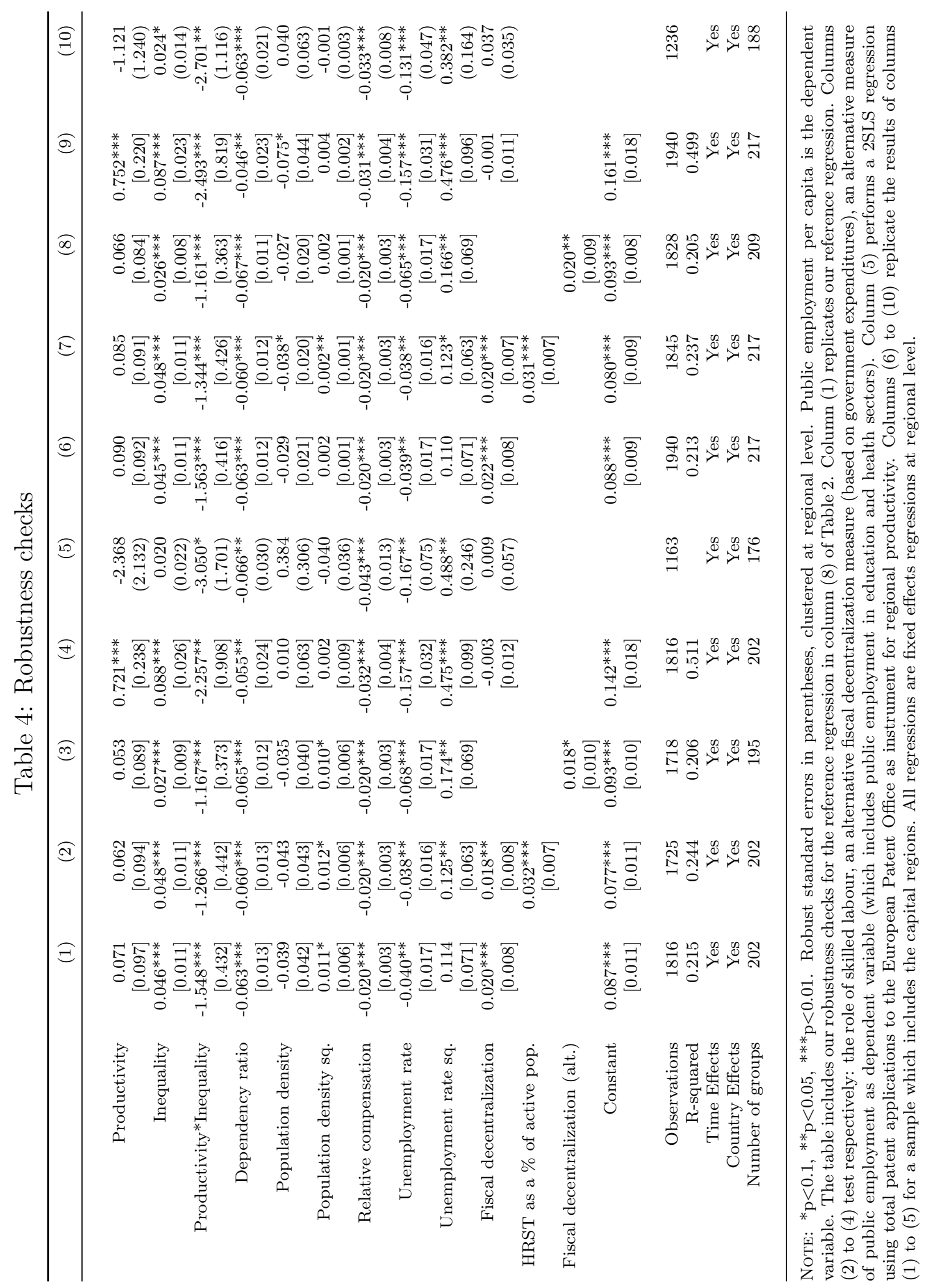


discussed in Section 2.2, public sector employment may directly reduce employment in the private sector, driving up marginal productivity. Finally, the most productive individuals and the entrepreneurial talents may be attracted by the public sector, given its potential advantages in terms of job security and wage premia. This could have a negative effect on productivity.

To address this challenge, we additionally consider instrumental variables estimations. Column (5) of Table 4 shows our 2SLS estimates, which takes the potential endogeneity of public employment into account. Our chosen instrument for regional productivity is the total number of patent applications to the European Patent Office (EPO) per million inhabitants. This variable can be considered sufficiently exogenous given that our main public employment variable does not include employment in education, research and health care, etc. ${ }^{14}$ While the significance of the coefficients is somewhat reduced in the 2SLS relative to our fixed effects benchmark, overall the 2SLS estimates confirm our key findings. We again find a negative relationship between regional productivity and the level of regional public employment, and this relationship is more pronounced in countries characterized by higher regional productivity differences. Quantitatively the effects are even stronger as is evident from the higher coefficient (in absolute terms) of the interaction term.

Finally, columns (6) to (10) test the role of outliers and replicate the specifications in columns (1)-(5) by using a sample which includes all the capital regions. The results confirm signs, magnitude and significance of all our key variables of interest reported in the previous columns.

\section{Conclusions}

Public employment can serve as an expenditure side tagging device to improve the efficiency of tax-transfer schemes. It allows targeting via local consumption of public goods, via the exploitation of regional differences in opportunity costs, and through a beneficial effect on incentive compatibility of the tax-transfer system. Using a panel data set of European regions from 17 countries, we find evidence that the regional distribution of public employment is consistent with our normative analysis. Public employment is significantly

\footnotetext{
${ }^{14}$ If regional productivity is endogenous, the interaction between regional productivity and inequality will be endogenous. Since inequality is measured by regional productivity dispersion, in principle it can be endogenous as well. However, since inequality is a country-level measure, at regional level it may be considered rather exogenous. In line with this, in our 2SLS estimates we consider both productivity and the interaction between productivity and inequality as endogenous variables, and we take inequality with a lag. As evidenced by the relevant tests, our endogenous regressors are jointly significant (Column (5): Anderson-Rubin Wald test Chi-sq(2)=11.59, P-val=0.0030; column (10): Anderson-Rubin Wald test Chi-sq(2) $=9.8, \mathrm{P}$-val $=0.0072)$. The instruments are in general significant in the auxiliary regressions.
} 
higher in low productivity regions and this relationship is significantly stronger in countries with a higher degree of regional inequality. These findings are robust to a number of different empirical specifications. Moreover, these findings are more pronounced in countries characterized by a relatively high stock of immigrants, or by relatively high unemployment, both important factors on the European policy agenda.

Finally, we would like to stress some caveats regarding the policy implications of our analysis. First, intervening in the labor market by adjusting public employment regionally may cause additional negative side effects, such as the potential sorting of talented individuals from the private sector into the public sector. Second, interregional migration affects the degree to which regional differentiation of public employment can be a sensible policy instrument. Finally, regionally differentiated public employment needs to be comprehensively compared to alternative policy instruments such as regionally differentiated grants, taxation, and regulation.

\section{A Appendix}

\section{A.1 Data description and sources}

All data at regional level are from Eurostat regional statistics. Public employment data have been kindly provided by the Eurostat staff. All remaining regional data can be found on the Eurostat website. Additional data at country level are from OECD.

Public employment: Public employment per capita. The number of people employed in the NACE sector "Public administration and defence; compulsory social security" (sector L, NACE rev. 1.1) divided by population. Source: Eurostat (Regional Labour Force StatisticsLFS). Period: 1995-2007. Geographical aggregation level: NUTS 2.

Public employment (edu-health): Public employment per capita (alternative measure). The number of people employed in the NACE sectors "Public administration and defence; compulsory social security" (sector L, NACE rev. 1.1), "Education" (sector M, NACE rev. 1.1),) and "Health and social work" (sector N, NACE rev. 1.1) divided by population. Source: Eurostat (Regional Labour Force Statistics-LFS ). Period: 1995-2007. Geographical aggregation level: NUTS 2.

Productivity: Wages and salaries per number of persons employed in the NACE sector "Manufacturing". Source: Eurostat (Regional structural business statistics). Period: 1995-2007. Geographical aggregation level: NUTS 2. Unit of measure: Millions of euro.

Inequality: Coefficient of variation of regional productivity. Regional productivity has been weighted by the population share of the corresponding region. Source: authors' calculation from Eurostat data. Period: 1995-2007. Geographical aggregation level: NUTS 0 (country level).

Population density: Total population per square kilometers. Source: Eurostat (Regional demographic statistics). Period: 1995-2007. Geographical aggregation level: NUTS 2. Unit of measure: Thousands.

Dependency ratio: Ratio of persons who are below 14 and above 64 years over the working age population. Source: Eurostat (Regional demographic statistics). Period: 1995-2007. Geographical aggregation level: NUTS 2.

Relative compensation: Ratio of public to private compensation per capita. Public compensation is compensation of persons engaged (total employment) in the NACE sector "Public 
administration and defence; compulsory social security". Private compensation is compensation of people engaged in the NACE sector "Manufacturing". Source: OECD (STAN). Period: 1995-2007. Geographical aggregation level: NUTS 0 (country level). Per capita public (private) compensation has been derived as the ratio between public (private) compensation and public (private) employment, taken from OECD (STAN).

Unemployment rate: Unemployment rate. Source: Eurostat (Regional Labour Force Statistics-LFS ). Period: 1995-2007. Geographical aggregation level: NUTS 2.

Fiscal decentralization: Fiscal decentralization (alternative measure). This measure is equal the ratio of the sum of local and regional tax revenue over total general government tax revenues. Source: OECD (OECD Fiscal Decentralization Database). Period: 1995-2007. Geographical aggregation level: NUTS 0 (country level).

Fiscal decentralization (alt.): Fiscal decentralization. This measure is equal to $1 \mathrm{mi}-$ nus the ratio of central government expenditures over total government expenditures. Source: IMF (Government Finance Statistics-GFS). Period: 1995-2007. Geographical aggregation level: NUTS 0 (country level).

HRST as a \% of active pop.: Human Resources in Science and Technology (HRST) as a percentage of active population. HRST includes those who have completed an education at the third level in a S\&T field or are employed in an occupation where such an education is normally required. Active population are individuals aged 25-64. Source: Eurostat (Regional Labour Force Statistics-LFS). Period: 1995-2007. Geographical aggregation level: NUTS 2.

Patent applications: Patent applications to the European Patent Office (EPO) per million inhabitants. Source: Eurostat (Regional Science and Technology Statistics). Period: 1995-2007. Geographical aggregation level: NUTS 2. 


\section{A.2 Pooled OLS Estimates}

Table 5: The determinants of public employment. Pooled OLS estimates

\begin{tabular}{|c|c|c|c|c|c|c|c|c|}
\hline & $(1)$ & (2) & (3) & (4) & (5) & (6) & (7) & (8) \\
\hline Productivity & $-0.394^{* * *}$ & $-0.384^{* * *}$ & 0.001 & 0.098 & 0.138 & 0.199 & 0.204 & 0.236 \\
\hline Inequality & [0.088] & $\begin{array}{c}{[0.090]} \\
0.015\end{array}$ & $\begin{array}{c}{[0.150]} \\
0.055^{* * *}\end{array}$ & $\begin{array}{c}{[0.163]} \\
0.069 * * *\end{array}$ & $\begin{array}{l}{[0.154]} \\
0.066^{* * *}\end{array}$ & $\begin{array}{c}{[0.159]} \\
0.067^{* * *}\end{array}$ & $\begin{array}{l}{[0.160]} \\
0.067^{* * *}\end{array}$ & $0.069 * * *$ \\
\hline & & {$[0.012]$} & {$[0.021]$} & {$[0.023]$} & [0.023] & {$[0.021]$} & {$[0.021]$} & {$[0.021]$} \\
\hline Productivity*Inequality & & & $\begin{array}{c}-2.660^{* * *} \\
{[0.777]}\end{array}$ & $\begin{array}{c}-2.935 * * * \\
{[0.885]}\end{array}$ & $\begin{array}{c}-2.653^{* * *} \\
{[0.847]}\end{array}$ & $\begin{array}{c}-2.712^{* * * *} \\
{[0.780]}\end{array}$ & $\begin{array}{c}-2.728^{* * *} \\
{[0.783]}\end{array}$ & $\begin{array}{c}-2.877^{* * * *} \\
{[0.805]}\end{array}$ \\
\hline Dependency ratio & & & & 0.002 & -0.003 & 0.001 & 0.001 & 0.001 \\
\hline & & & & {$[0.013]$} & {$[0.013]$} & [0.014] & {$[0.014]$} & {$[0.014]$} \\
\hline Population density & & & & $\begin{array}{c}-0.003^{* *} \\
{[0.001]}\end{array}$ & $\begin{array}{c}-0.013^{* * *} \\
{[0.003]}\end{array}$ & $\begin{array}{c}-0.013^{* * *} \\
{[0.003]}\end{array}$ & $\begin{array}{c}-0.013^{* * *} \\
{[0.003]}\end{array}$ & $\begin{array}{c}-0.013^{* * *} \\
{[0.003]}\end{array}$ \\
\hline Population density sq. & & & & & $\begin{array}{c}0.004^{* * *} \\
{[0.001]}\end{array}$ & $\begin{array}{c}0.004^{* * *} \\
{[0.001]}\end{array}$ & $\begin{array}{c}0.004^{* * *} \\
{[0.001]}\end{array}$ & $\begin{array}{c}0.004^{* * *} \\
{[0.001]}\end{array}$ \\
\hline Relative compensation & & & & & & $\begin{array}{c}-0.019^{* * *} * \\
{[0.003]}\end{array}$ & $\begin{array}{c}-0.019 * * * \\
{[0.003]}\end{array}$ & $\begin{array}{c}-0.021^{* * *} \\
{[0.003]}\end{array}$ \\
\hline Unemployment rate & & & & & & 0.017 & 0.031 & 0.032 \\
\hline Unemployment rate sq. & & & & & & & $\begin{array}{l}-0.055 \\
{[0.095]}\end{array}$ & $\begin{array}{l}-0.057 \\
{[0.097]}\end{array}$ \\
\hline Fiscal decentralization & & & & & & & & $\begin{array}{c}0.024^{* * *} \\
{[0.008]}\end{array}$ \\
\hline Constant & $\begin{array}{c}0.026^{* * *} \\
{[0.001]}\end{array}$ & $\begin{array}{c}0.024^{* * *} \\
{[0.002]}\end{array}$ & $\begin{array}{c}0.019^{* * *} \\
{[0.003]}\end{array}$ & $\begin{array}{c}0.016^{* *} \\
{[0.007]}\end{array}$ & $\begin{array}{c}0.020^{* * *} \\
{[0.007]}\end{array}$ & $\begin{array}{c}0.028^{* *} \\
{[0.011]}\end{array}$ & $\begin{array}{c}0.028^{* *} \\
{[0.011]}\end{array}$ & $\begin{array}{c}0.024^{* *} \\
{[0.012]}\end{array}$ \\
\hline Observations & 2296 & 2296 & 2296 & 2060 & 2060 & 1816 & 1816 & 1816 \\
\hline R-squared & 0.422 & 0.423 & 0.427 & 0.394 & 0.422 & 0.369 & 0.369 & 0.37 \\
\hline Time Effects & Yes & Yes & Yes & Yes & Yes & Yes & Yes & Yes \\
\hline Country Effects & Yes & Yes & Yes & Yes & Yes & Yes & Yes & Yes \\
\hline Number of groups & 221 & 221 & 221 & 219 & 219 & 202 & 202 & 202 \\
\hline
\end{tabular}

Note: ${ }^{*} \mathrm{p}<0.1,{ }^{*} \mathrm{p}<0.05, * * * \mathrm{p}<0.01$. Robust standard errors in parentheses, clustered at regional level. R-squared is the adjusted R-squared. Regional public employment per capita in public administration is the dependent variable.

\section{References}

[1] Akerlof, G., 1978, "The Economics of Tagging as applied to the Optimal Income tax", American Economic Review, 68, 8-19.

[2] Alesina, A., Baquir, R. and W. Easterly, 2000, "Redistributive Public Employment", Journal of Urban Economics, 48(2), 219-241.

[3] Alesina, A., Danninger, S. and M. Rostagno, 2001, "Redistribution through Public Employment: The Case of Italy", IMF Staff Papers, 48(3), 447-475.

[4] Blackorby, C. and C. Brett, 2004, "Production Efficiency and the Direct-Indirect Tax Mix", Journal of Public Economic Theory, 6(1), 165-180.

[5] Blomquist, S., V. Christiansen and Luca Micheletto, 2010, "Public Provision of Private Goods and Nondistortionary Marginal Tax Rates", American Economic Journal: Economic Policy, 2(2), 1-27.

[6] Blumkin, T., Y. Margalioth and E. Sadka, 2009, "Incorporating Affirmative Action into the Welfare State", Journal of Public Economics, 93(9-10), 1027-1035.

[7] Boadway, R. and P. Pestieau, 2006, "Tagging and Redistributive Taxation", Annales d'Économie et de Statistique, 83/84, 123-147. 
[8] Borge, L.-E. and E. Matsen, 2004, "Public Employment and Regional Risk Sharing", Scandinavian Journal of Economics, 106(2), 215-230.

[9] de la Fuente, A., 2004, "Second-best redistribution through public investment: a characterization, an empirical test and an application to the case of Spain", Regional Science and Urban Economics, 34, 489-503.

[10] Gelb, A., Knight, J.B. and R.H. Sabot, 1991, "Public Sector Employment, Rent-Seeking and Economic Growth", Economic Journal, 101, 1186-1199.

[11] Jaimovich, E. and J.P. Rud, 2009, "Excessive Public Employment and Rent-Seeking Traps", Collegio Carlo Alberto Working Paper No. 118.

[12] Kessing, S.G. and K.A. Konrad, 2008, "Time Consistency and Bureaucratic Budget Competition", Economic Journal, 118, 1-15.

[13] Kessing, S.G. and C. Strozzi, 2012, "The Regional Distribution of Public Employment: Theory and Evidence", IZA Discussion Paper No. 6449

[14] López-de-Silanes, F., Shleifer, A. and R. Vishny, 1989, "Privatization in the United States", Rand Journal of Economics, 28, 447-471.

[15] Martínez-Vázquez, J. and Y. Ming-Hung, 2009, "Fiscal Decentralization and Public Sector Employment: A Cross-Country Analysis", Institudo de Estudios Fiscales Working Paper No. $13 / 09$.

[16] Nichols, A.L. and R.Zeckhauser, 1982, "Targeting Transfers through Restrictions on Recipients", American Economic Review, Papers and Proceedings, 72(2), 372-377.

[17] Pinotti, P., 2015, "The Economic Costs of Organised Crime: Evidence from Southern Italy", Economic Journal, 125, 203-232.

[18] Rodrik, D. 2000, "What drives Public Employment in Developing Countries?" Review of Development Economics, 4, 229-243.

[19] Stiglitz, J.E., 1982, "Self-Selection and Pareto Efficient Taxation", Journal of Public Economics $17(2), 213-240$.

[20] Wilson, J.D., 1982, "The Optimal Public Employment Policy", Journal of Public Economics, 17(2), 241-258. 